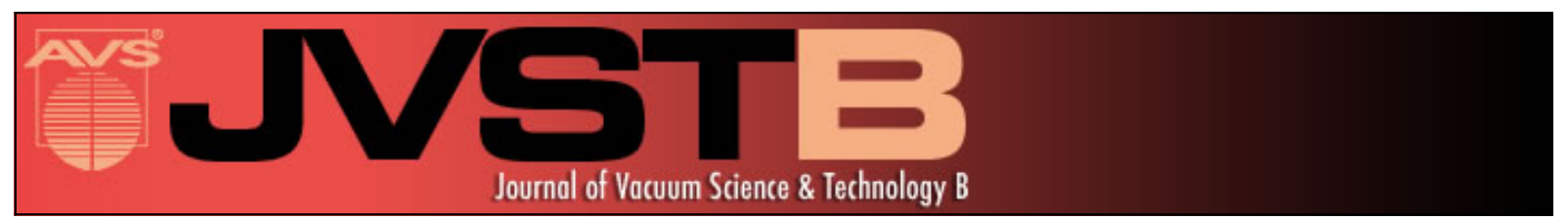

\title{
Minority carrier lifetime of lattice-matched CdZnTe alloy grown on InSb substrates using molecular beam epitaxy
}

Shi Liu, Xin-Hao Zhao, Calli Campbell, Michael J. DiNezza, Yuan Zhao, and Yong-Hang Zhang

Citation: Journal of Vacuum Science \& Technology B 33, 011207 (2015); doi: 10.1116/1.4905289

View online: http://dx.doi.org/10.1116/1.4905289

View Table of Contents: http://scitation.aip.org/content/avs/journal/jvstb/33/1 ?ver=pdfcov

Published by the AVS: Science \& Technology of Materials, Interfaces, and Processing

\section{Articles you may be interested in}

Determination of $\mathrm{CdTe}$ bulk carrier lifetime and interface recombination velocity of $\mathrm{CdTe} / \mathrm{MgCdTe}$ double heterostructures grown by molecular beam epitaxy

Appl. Phys. Lett. 105, 252101 (2014); 10.1063/1.4904993

Impact of dislocations on minority carrier electron and hole lifetimes in GaAs grown on metamorphic SiGe substrates

Appl. Phys. Lett. 84, 3447 (2004); 10.1063/1.1736318

Effect of dislocations on minority carrier lifetime in $\mathrm{HgCdTe}$

J. Appl. Phys. 95, 2467 (2004); 10.1063/1.1644039

Radiative and nonradiative recombination processes in lattice-matched ( $\mathrm{Cd}, \mathrm{Zn}) \mathrm{O} /(\mathrm{Mg}, \mathrm{Zn}) \mathrm{O}$ multiquantum wells Appl. Phys. Lett. 77, 1632 (2000); 10.1063/1.1308540

$\mathrm{N}$-type doping of lattice-matched $\mathrm{ZnCdSe}$ and $\mathrm{Zn} \times \mathrm{Cd}$ y Mg 1-x-y Se epilayers on InP using $\mathrm{ZnCl} 2$ J. Appl. Phys. 84, 1472 (1998); 10.1063/1.368210

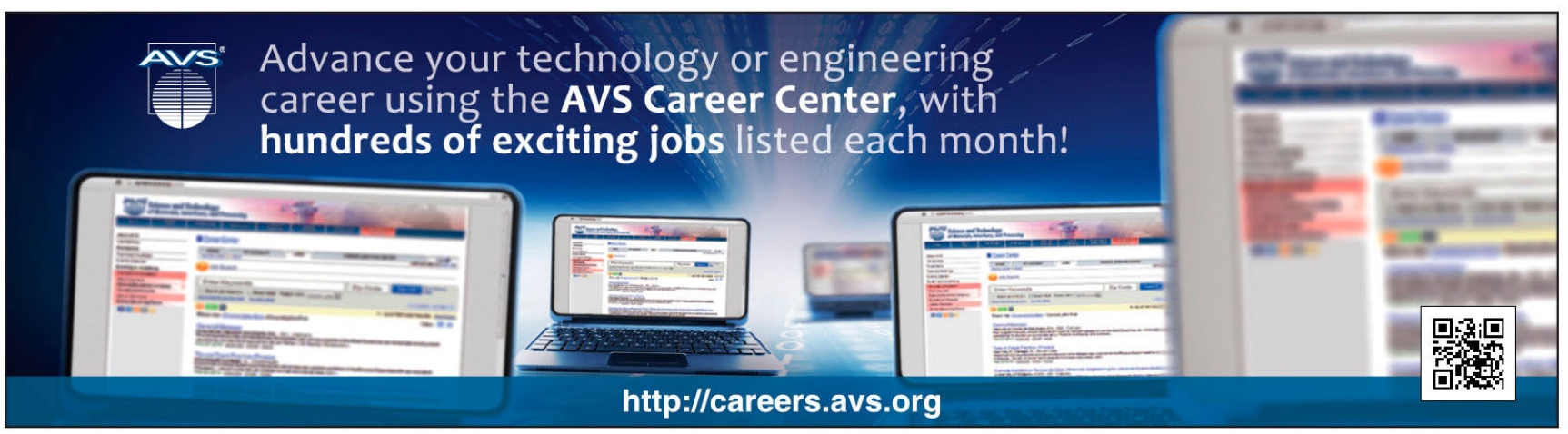




\title{
Minority carrier lifetime of lattice-matched CdZnTe alloy grown on InSb substrates using molecular beam epitaxy
}

\author{
Shi Liu \\ Center for Photonics Innovation and School of Electrical, Computer and Energy Engineering, \\ Arizona State University, Tempe, Arizona 85287 \\ Xin-Hao Zhao and Calli Campbell \\ Center for Photonics Innovation and School for Engineering of Matter, Transport and Energy, \\ Arizona State University, Tempe, Arizona 85287 \\ Michael J. DiNezza, Yuan Zhao, and Yong-Hang Zhang ${ }^{\text {a) }}$ \\ Center for Photonics Innovation and School of Electrical, Computer and Energy Engineering, \\ Arizona State University, Tempe, Arizona 85287
}

(Received 2 November 2014; accepted 19 December 2014; published 6 January 2015)

\begin{abstract}
A CdZnTe/MgCdTe double-heterostructure (DH) consisting of a $3 \mu \mathrm{m}$ thick $\mathrm{Cd}_{0.9946} \mathrm{Zn}_{0.0054} \mathrm{Te}$ middle layer that is lattice-matched to an InSb substrate has been grown using molecular beam epitaxy. A long carrier lifetime of $3.4 \times 10^{2}$ ns has been demonstrated at room temperature, which is approximately three times as long as that of a $\mathrm{CdTe} / \mathrm{MgCdTe} \mathrm{DH}$ with identical layer thickness. This substantial improvement is due to the reduction in misfit dislocation density in the CdZnTe alloy. In contrast, a CdTe/MgCdTe DH with $3 \mu$ m thick CdTe layer grown on an InSb substrate exhibits a strain relaxation of $\sim 30 \%$, which leads to a wider $\mathrm{x}$-ray diffraction peak, a weaker integrated photoluminescence intensity, and a shorter minority carrier lifetime of $1.0 \times 10^{2} \mathrm{~ns}$. These findings indicate that CdZnTe lattice-matched to InSb has great potential as applied to high-efficiency solar cells as well as virtual substrates for high-performance large-area $\mathrm{HgCdTe}$ focal plane arrays. (C) 2015 American Vacuum Society. [http://dx.doi.org/10.1116/1.4905289]
\end{abstract}

\section{INTRODUCTION}

There has been growing interest in CdTe solar cells in recent years due to continuing improvements in device performance and market share. The efficiency record of polycrystalline CdTe solar cells has been frequently broken, recently reaching $21.0 \%{ }^{1}$ However, this is still more than ten absolute percent lower than the Shockley-Queisser limit. Although the short-circuit current density is already close to the theoretical limit, there is still significant room for improvement in open-circuit voltage $\left(V_{\mathrm{OC}}\right)$ and fill factor, which are currently below $0.9 \mathrm{~V}$ and $80 \%$, respectively, for most devices. ${ }^{2}$ Such imperfections are believed to be due to large defect density, short minority carrier lifetime and so on. The use of monocrystalline CdTe is anticipated to improve the $V_{\mathrm{OC}}$ dramatically because of its better material quality and longer carrier lifetime. Several research efforts have demonstrated long carrier lifetimes in both epitaxial $\mathrm{CdTe}$ on InSb and bulk CdTe, along with a $V_{\mathrm{OC}}$ of greater than $0.9 \mathrm{~V}$ in monocrystalline $\mathrm{CdTe}$ solar cells. ${ }^{3-9}$ Regardless of these new achievements, CdTe is not completely lattice-matched to InSb, which may cause material quality degradation when the CdTe epilayer is beyond a certain thickness (e.g., $2 \mu \mathrm{m}$ ). This problem can be circumvented by adding a small fraction of $\mathrm{Zn}$ into $\mathrm{CdTe}$ in order to form a CdZnTe alloy that is completely lattice-matched to $\mathrm{InSb}$ and exhibits a negligible increase in bandgap. A longer minority carrier lifetime is thus expected in the CdZnTe epilayer, especially when the layer is more than $2 \mu \mathrm{m}$ thick,

a)Electronic mail: yhzhang@asu.edu since the misfit dislocation density is lower in this latticematched material system. Moreover, CdZnTe alloys grown on InSb, with tunable $\mathrm{Zn}$ compositions, can provide highquality virtual substrates for $\mathrm{HgCdTe}$ growth. The advantages of this approach include: (1) CdZnTe is chemically compatible with, and lattice-matched to, $\mathrm{HgCdTe} ;{ }^{10,11}$ (2) InSb substrates are of both high quality and low cost which overcomes the existing cost issues of CdZnTe substrates that impede their widespread application in large-area focal plane arrays; ${ }^{10,11}$ and (3) CdZnTe on InSb offers better material quality compared to other alternative substrate techniques, such as $\mathrm{CdTe} / \mathrm{Si},{ }^{12} \mathrm{CdTe} / \mathrm{Ge},{ }^{13} \mathrm{CdTe} / \mathrm{GaAs},{ }^{14} \mathrm{CdTe} / \mathrm{GaSb},{ }^{15}$ and $\mathrm{InSb},{ }^{16}$ and thus has the feasibility to achieve high performance in long-wavelength infrared detectors.

\section{EXPERIMENT}

In this paper, we report the demonstration of a high-quality $\mathrm{Cd}_{0.9946} \mathrm{Zn}_{0.0054} \mathrm{Te} / \mathrm{Mg}_{0.24} \mathrm{Cd}_{0.76} \mathrm{Te}$ double-heterostructure (DH) grown on an InSb (100) substrate by molecular beam epitaxy (MBE) and characterized by high-resolution x-ray diffraction (XRD), steady-state photoluminescence (PL), and timeresolved photoluminescence (TRPL). Two sets of samples have been studied here. The first set consists of samples A to C (growth run numbers are A1654, A1656, and A1659, respectively), which are $1 \mu \mathrm{m} \mathrm{CdZnTe} \mathrm{layers} \mathrm{grown} \mathrm{under} \mathrm{various} \mathrm{Zn}$ fluxes, for the purpose of lattice-match calibration. The second set consists of samples D and $\mathrm{E}$ (growth run numbers are A1667 and A1666, respectively), which are $3 \mu \mathrm{m} \mathrm{CdTe/}$ $\mathrm{Mg}_{0.24} \mathrm{Cd}_{0.76} \mathrm{Te}$ and $\mathrm{Cd}_{0.9946} \mathrm{Zn}_{0.0054} \mathrm{Te} / \mathrm{Mg}_{0.24} \mathrm{Cd}_{0.76} \mathrm{Te} \mathrm{DHs}$, for structural and optical properties comparisons. The 
schematic layer structures of samples D and E are shown in Fig. 1. The $30 \mathrm{~nm} \mathrm{MgCdTe}$ barrier layers, with $\mathrm{Mg}$ compositions of $24 \%$, prevent photogenerated carriers from reaching the top surface and bottom buffer/substrate interface to recombine nonradiatively. The $\mathrm{Zn}$ composition in the CdZnTe alloy is designed to be $0.54 \%$ so that the alloy is perfectly latticematched to the InSb substrate.

All the samples are grown using a VG V80H dualchamber MBE system with separate III-V and II-VI growth chambers connected by an ultrahigh vacuum (UHV) transfer chamber. The oxide removal process of InSb substrates starts with an initial substrate temperature ramp to a thermocouple reading of $500{ }^{\circ} \mathrm{C}$ at $20^{\circ} \mathrm{C} / \mathrm{min}$. Then, the temperature is further ramped up at a slower rate of $5^{\circ} \mathrm{C} / \mathrm{min}$ in $5^{\circ} \mathrm{C}$ intervals, with a 3 min pause after each ramp to prevent the substrate from overheating, until a pyrometer reading of $475-480^{\circ} \mathrm{C}$ is reached. Such a careful temperature ramp is necessary because the InSb oxide removal temperature is very close to the InSb melting point. The substrates are kept at this temperature for one hour, and the completion of oxide removal is then indicated by streaky pseudo- $(1 \times 3)$ reflection high energy electron diffraction patterns. Next, the substrate temperature is brought down to $390{ }^{\circ} \mathrm{C}$ for the $500 \mathrm{~nm} \mathrm{InSb}$ buffer growth, with a growth rate of $9.1 \mathrm{~nm} / \mathrm{min}$ and a Sb/In flux ratio of 1.5 . After the III-V growth, the samples are transferred to the II-VI chamber under UHV, which avoids surface oxidation and contamination. The II-VI layers are grown at $265^{\circ} \mathrm{C}$ with a growth rate of $9.6 \mathrm{~nm} / \mathrm{min}$ and a $\mathrm{Cd} / \mathrm{Te}$ flux ratio of 1.5 . Detailed growth procedures of II-VI layers can be found in the previous publication. ${ }^{3}$

\section{RESULTS AND DISCUSSION}

The lattice-match calibration of the CdZnTe alloy to the InSb substrate is carried out by measuring the XRD patterns of samples A to $\mathrm{C}$ and from there determining the $\mathrm{Zn}$ composition. The $\omega / 2 \theta$ scans at the (004) orientation of samples A to $\mathrm{C}$, which are grown under $\mathrm{Zn}$ cell temperatures of 235 , 245 , and $255^{\circ} \mathrm{C}$, respectively, are shown in Fig. 2. It is observed that there are two separate peaks in samples A and $\mathrm{B}$ that correspond to the strained CdZnTe layer and the $\mathrm{InSb}$
Sample D

\begin{tabular}{|c|}
\hline CdTe cap \\
\hline $\mathrm{Mg}_{0.24} \mathrm{Cd}_{0.76} \mathrm{Te}$ barrier \\
\hline CdTe \\
\hline $\mathrm{Mg}_{0.24} \mathrm{Cd}_{0.76}$ Te barrier \\
\hline CdTe buffer \\
\hline InSb buffer \\
\hline InSb substrate \\
\hline
\end{tabular}

Sample E

\begin{tabular}{|c|c|}
\hline $10 \mathrm{~nm}$ & $\mathrm{Cd}_{0.9946} \mathrm{Zn}_{0.0054} \mathrm{Te}$ cap \\
\hline $30 \mathrm{~nm}$ & $\mathrm{Mg}_{0.24} \mathrm{Cd}_{0.76} \mathrm{Te}$ barrier \\
\hline $00 \mathrm{n}$ & $\mathrm{Cd}_{0.9946} \mathrm{Zn}_{0.0054} \mathrm{Te}$ \\
\hline $30 \mathrm{~nm}$ & $\mathrm{Mg}_{0.24} \mathrm{Cd}_{0.76}$ Te barrier \\
\hline $500 \mathrm{~nm}$ & $\mathrm{Cd}_{0.9946} \mathrm{Zn}_{0.0054} \mathrm{Te}$ buffer \\
\hline $500 \mathrm{~nm}$ & InSb buffer \\
\hline & InSb substrate \\
\hline
\end{tabular}

FIG. 1. Schematic layer structures of sample D: CdTe/ $\mathrm{Mg}_{0.24} \mathrm{Cd}_{0.76} \mathrm{Te} \mathrm{DH}$, and sample E: $\mathrm{Cd}_{0.9946} \mathrm{Zn}_{0.0054} \mathrm{Te} / \mathrm{Mg}_{0.24} \mathrm{Cd}_{0.76} \mathrm{Te} \mathrm{DH}$.

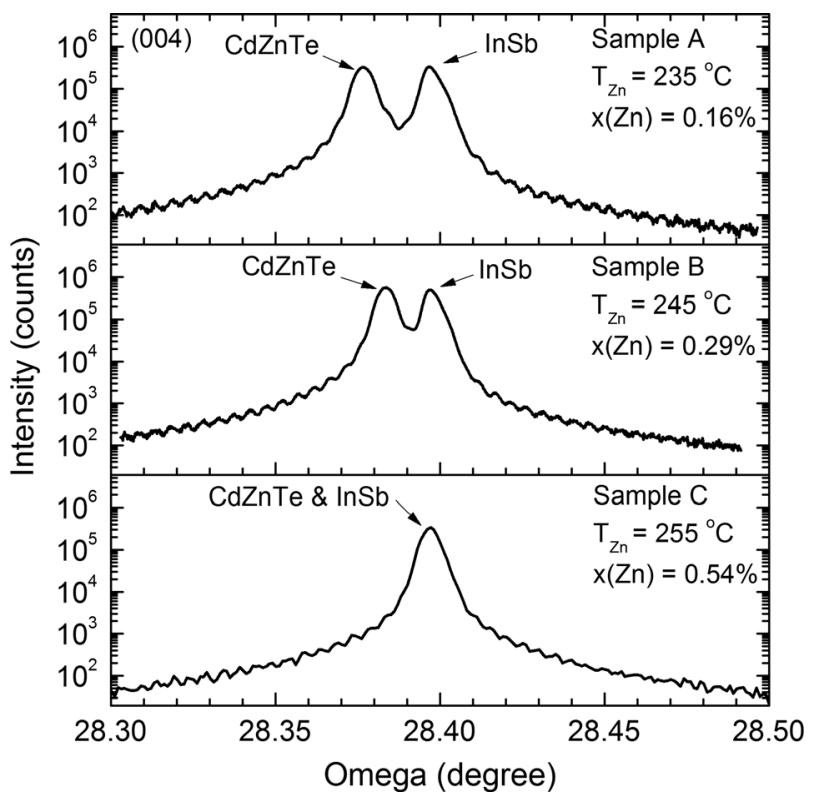

FIG. 2. High-resolution x-ray diffraction (004) patterns of samples A, B, and $\mathrm{C}$, which have $1 \mu \mathrm{m}$ CdZnTe layers on InSb substrates, showing that a complete lattice match is achieved.

substrate. However, in sample C, the two peaks merge together, indicating that a complete lattice match is reached. The $\mathrm{Zn}$ compositions listed in the figure are obtained by fitting the measured diffraction patterns based on the published structural parameters of ZnTe, CdTe, ${ }^{17}$ and InSb. The narrow full-width at half-maximums (FWHMs) of the CdZnTe peaks, which are comparable to those of InSb substrates, along with the clear Pendellösung fringes are indicators of high quality CdZnTe layers and smooth CdZnTe/InSb interfaces. The (004) $\omega / 2 \theta$ scans are also performed for samples $\mathrm{D}$ and $\mathrm{E}$, and the experimental and simulated diffraction patterns are shown in Fig. 3. The diffraction pattern of sample D clearly shows two separate peaks representing $\mathrm{InSb}$ and CdTe, and a strain relaxation of $\sim 30 \%$ for the CdTe layer is determined by XRD pattern simulation. In contrast, only one peak is present in the diffraction pattern of sample $\mathrm{E}$, which means that the CdZnTe layer and the InSb substrate are lattice-matched. A larger FWHM of 22.6 arc sec observed for sample D compared to that for sample E (16.6 arc sec) shows degraded material quality due to strain relaxation. The broad peaks of the $\mathrm{MgCdTe}$ barrier layers and the Pendellösung fringes are observed in both samples, indicating the high material quality of these layers and smooth $\mathrm{MgCdTe} / \mathrm{Cd}(\mathrm{Zn}) \mathrm{Te}$ interfaces.

The steady-state PL spectra of samples D and E are measured at room temperature using a $532 \mathrm{~nm}$ diode pumped solid state laser as a pumping source. The laser excitation power density is kept at $100 \mathrm{~mW} / \mathrm{cm}^{2}$ to mimic AM $1.5 \mathrm{G}$ solar radiation and to protect the II-VI layers from thermal damage by laser heating. As shown in Fig. 4, sample D has a PL peak wavelength of $825 \mathrm{~nm}$, which corresponds to a band-to-band transition energy of $1.503 \mathrm{eV}$, while sample $\mathrm{E}$ has a PL peak wavelength of $824 \mathrm{~nm}$, which corresponds to a band-to-band transition energy of $1.505 \mathrm{eV}$. Such a slight 


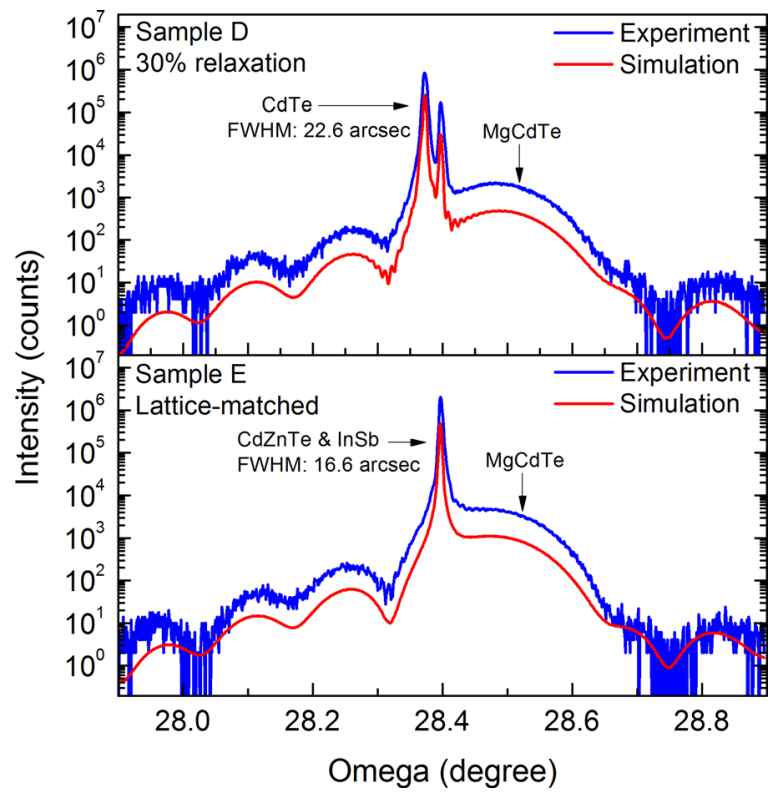

FIG. 3. (Color online) High-resolution x-ray diffraction (004) patterns for samples D ( $3 \mu \mathrm{m} \mathrm{CdTe} / \mathrm{MgCdTe} \mathrm{DH})$ and $\mathrm{E}(3 \mu \mathrm{m} \mathrm{CdZnTe} / \mathrm{MgCdTe} \mathrm{DH})$. The $3 \mu \mathrm{m}$ CdTe layer has a relaxation of $\sim 30 \%$, while the $3 \mu \mathrm{m} \mathrm{CdZnTe}$ layer is completely lattice-matched to the InSb substrate. They also clearly show that the CdTe peak has a FWHM of 22.6 arc sec, compared to the value of 16.6 arc sec for the $\mathrm{CdZnTe}$ peak, indicating that strain relaxation results in degraded material quality.

increase in the transition energy indicates that the bandgap increase caused by introducing $0.54 \% \mathrm{Zn}$ in the CdTe binary is negligible. This is desirable for solar cells since any deviation from the optimal bandgap for single-junction solar cells should be avoided. The integrated PL intensity of sample E is at least one order of magnitude higher than that of sample D. Note that although the lattice mismatch between CdTe

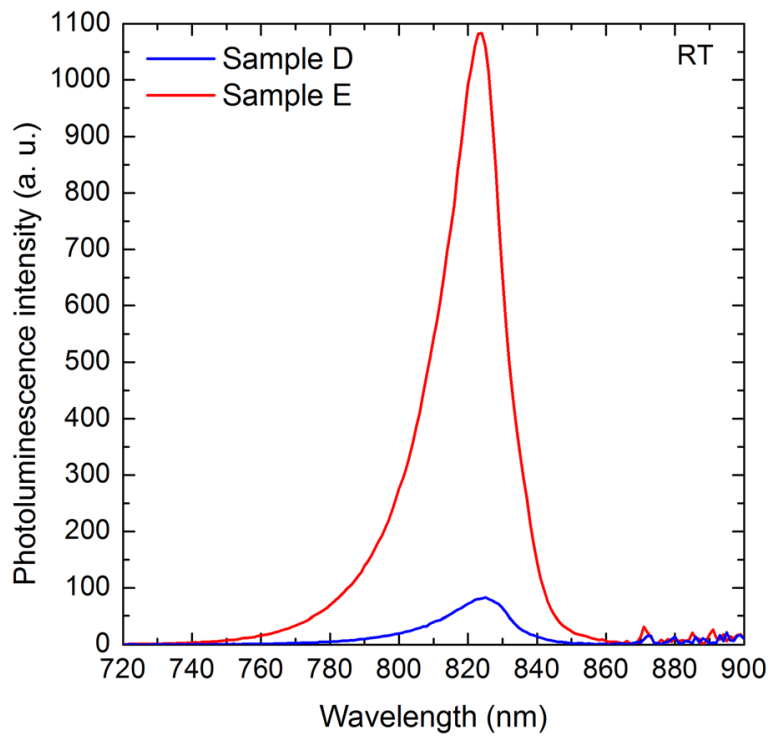

FIG. 4. (Color online) Room temperature photoluminescence spectra of samples $\mathrm{D}$ and $\mathrm{E}$, showing that the integrated photoluminescence intensity of the $\mathrm{CdZnTe} / \mathrm{MgCdTe} \mathrm{DH}$ is over one order of magnitude stronger than that of the $\mathrm{CdTe} / \mathrm{MgCdTe} \mathrm{DH}$.

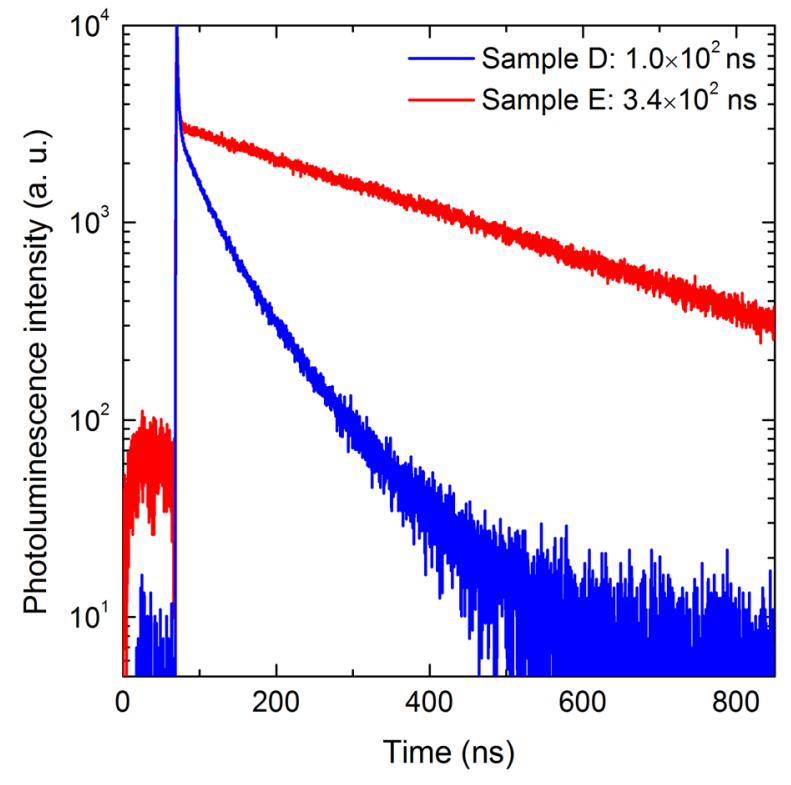

FIG. 5. (Color online) Time-resolved photoluminescence decays of samples $\mathrm{D}$ and $\mathrm{E}$ at room temperature, showing a significantly improved minority carrier lifetime, achieved by replacing CdTe with lattice-matched CdZnTe in the $3 \mu \mathrm{m}$ DH design. The longest lifetime of $3.4 \times 10^{2} \mathrm{~ns}$ is observed.

and InSb is only $0.03 \%$, the optical properties of the CdTe layer degrade noticeably due to the large density of misfit dislocations generated as a result of strain relaxation.

Figure 5 shows the room temperature PL decays of samples D and E measured by a time-correlated single photon counting system. The samples are excited by an ultrafast Ti:Sapphire laser with a $750 \mathrm{~nm}$ emission wavelength, a 130 fs pulse duration, and a $0.8 \mathrm{MHz}$ repetition rate. The luminescence signal is detected by a spectrometer equipped with a high-speed microchannel plate photomultiplier tube, with the detection wavelength set at $820 \mathrm{~nm}$. The minority carrier lifetimes of both samples are determined by fitting the tails of the decay curves, and are listed in Fig. 5. Sample E has a much longer measured lifetime $\left(3.4 \times 10^{2} \mathrm{~ns}\right)$ than that of sample $\mathrm{D}\left(1.0 \times 10^{2} \mathrm{~ns}\right)$, which again proves the necessity of the lattice match to maintain low defect density and long carrier lifetime for a thick epilayer. Table I summarizes the strain relaxations, XRD FWHMs, integrated PL intensities and minority carrier lifetimes of samples D and E. These findings consistently prove that better structural and optical qualities are obtained in lattice-matched CdZnTe as opposed to CdTe grown on InSb substrates.

TABLE I. Strain relaxations, XRD FWHMs, integrated PL intensities, and minority carrier lifetimes of sample D: $\mathrm{CdTe} / \mathrm{MgCdTe} \mathrm{DH}$, and sample E: CdZnTe/MgCdTe DH.

\begin{tabular}{lcc}
\hline \hline Sample & $\mathrm{D}$ & $\mathrm{E}$ \\
\hline Strain relaxation in Cd(Zn)Te layer (\%) & 30 & 0 \\
XRD FWHM of Cd(Zn)Te layer (arc sec) & 22.6 & 16.6 \\
Integrated PL intensity (a.u.) & 2556 & 29717 \\
Carrier lifetime (ns) & $1.0 \times 10^{2}$ & $3.4 \times 10^{2}$ \\
\hline \hline
\end{tabular}




\section{SUMMARY}

In summary, a CdZnTe ternary alloy completely latticematched to an InSb substrate has been demonstrated with accurate composition control using MBE. The Zn composition is determined to be $0.54 \%$ using XRD. Structural and optical properties comparisons have been carried out for $3 \mu \mathrm{m} \mathrm{CdTe} / \mathrm{MgCdTe} \mathrm{DH}$ and $\mathrm{CdZnTe} / \mathrm{MgCdTe} \mathrm{DH}$ samples grown on InSb substrates. Despite the fact that the lattice mismatch between CdTe and InSb is only $0.03 \%$, the $3 \mu \mathrm{m}$ CdTe layer has a relaxation of $\sim 30 \%$, and its (004) XRD peak is wider than that of a $3 \mu \mathrm{m}$ lattice-matched $\mathrm{CdZnTe}$ layer. It has also been observed that the $\mathrm{CdZnTe} / \mathrm{MgCdTe}$ DH sample shows an integrated PL intensity one order of magnitude higher than, and a carrier lifetime three times as long as, those of the $\mathrm{CdTe} / \mathrm{MgCdTe} \mathrm{DH}$ sample. The longest carrier lifetime is measured as $3.4 \times 10^{2} \mathrm{~ns}$ for the CdZnTe/ $\mathrm{MgCdTe} \mathrm{DH}$. These comparisons show the excellent material quality of a lattice-matched CdZnTe alloy grown on an InSb substrate, and manifest its great potential in highefficiency solar cells and large-area focal plane arrays.

\section{ACKNOWLEDGMENTS}

The authors would like to thank Su Lin for assistance with TRPL measurements, and Martyn Fisher for manuscript revision. This work was partially supported by AFOSR (Grant No. FA9550-12-1-0444), and National Science Foundation Graduate Research Fellowship (Grant No. DGE0802261). The authors gratefully acknowledge the use of facilities in the LeRoy Eyring Center for Solid State Science at Arizona State University.

${ }^{1}$ First Solar press release, 5 Aug 2014. First Solar achieves world's highest CdTe solar cell efficiency of $21.0 \%$, see http://investor.firstsolar.com/ releasedetail.cfm?ReleaseID $=864426$.

${ }^{2}$ T. A. Gessert et al., Sol. Energy Mater. Sol. Cells 119, 149 (2013).

${ }^{3}$ M. J. DiNezza, X.-H. Zhao, S. Liu, A. P. Kirk, and Y.-H. Zhang, Appl. Phys. Lett. 103, 193901 (2013).

${ }^{4}$ A. P. Kirk, M. J. DiNezza, S. Liu, X.-H. Zhao, and Y.-H. Zhang, Proceedings of the 39th IEEE Photovoltaic Specialists Conference, Tampa, FL, 16-21 June 2013, pp. 2512-2517.

${ }^{5}$ X.-H. Zhao, M. J. DiNezza, S. Liu, S. Lin, Y. Zhao, and Y.-H. Zhang, J. Vac. Sci. Technol., B 32, 040601 (2014).

${ }^{6}$ X.-H. Zhao, M. J. DiNezza, S. Liu, C. Campbell, Y. Zhao, and Y.-H. Zhang, Appl. Phys. Lett. 105, 252101 (2014).

${ }^{7}$ D. Kuciauskas, A. Kanevce, J. M. Burst, J. N. Duenow, R. Dhere, D. S. Albin, D. H. Levi, and R. K. Ahrenkiel, IEEE J. Photovoltaics 3, 1319 (2013).

${ }^{8}$ D. Kuciauskas, A. Kanevce, P. Dippo, S. Seyedmohammadi, and R. Malik, IEEE J. Photovoltaics 5, 366 (2014).

${ }^{9}$ J. N. Duenow, J. M. Burst, D. S. Albin, D. Kuciauskas, S. W. Johnston, R. C. Reedy, and W. K. Metzger, Appl. Phys. Lett. 105, 053903 (2014).

${ }^{10}$ A. Rogalski, Rep. Prog. Phys. 68, 2267 (2005).

${ }^{11}$ O. Gravarnd et al., J. Electron. Mater. 42, 3349 (2013).

${ }^{12}$ R. Sporken, S. Sivananthan, K. K. Mahavadi, G. Monfroy, M. Boukerche, and J. P. Faurie, Appl. Phys. Lett. 55, 1879 (1989).

${ }^{13}$ J. P. Zanatta et al., J. Electron. Mater. 35, 1231 (2006).

${ }^{14}$ R. N. Jacobs et al., J. Electron. Mater. 41, 2707 (2012).

${ }^{15}$ W. Lei, R. J. Gu, J. Antoszewski, J. Dell, and L. Faraone, J. Electron. Mater. 43, 2788 (2014).

${ }^{16}$ T. J. de Lyon et al., J. Electron. Mater. 39, 1058 (2010).

${ }^{17}$ S. Adachi, Handbook on Physical Properties of Semiconductors, II-VI Compound Semiconductors (Kluwer Academic, Boston, MA, 2004), Vol. III, pp. 212 and 360. 